ing list, one (E. tricostata, if my memory serves aright) seems to be entirely devoid of this secretion, but yet has the same habit of standing erect. These beetles are the veritable skunks of their order, and doubtless, like their ill-scented superiors, find protection in their comparatively as formidable weapon. They are apterous. and slow in their more- ments, coming out from their hiding places when the sun is declining, and feed upon dead matter or excrements. On the bare plains they are readily seen, and I doubt not that they find protection from birds, and perhaps from skunks also, by means of their secretion.

[For further information on this subject, see Rec., r430.]

\title{
A CURIOUS HABIT OF CALLOSAMIA PROMETHEA.
}

By JOHN George JACK, Chateauguay basin, P. Q., CANAda.

Fon several years $I$ have been very much puzzled, in summer, to account for numbers of green leaves, some being partly eaten, found on the ground beneath trees having long petioled leaves, such as maples and poplars, the petioles of which apparently had been eaten through by some insect. Last summer, while in New Jersey, I noticed similar occurrences beneath a sweet gum tree, Liquidambar styracifua, and upon looking for the cause I found that it was the work of nearly full grown larvae of Callosamia promethea, which were feeding on the foliage. The petioles of Liquidambar leaves are usually very long (from 5 to ro $\mathrm{cm}$.) and quite slender.

To get at the leaves the caterpillar was either obliged to abandon the branch of the tree and crawl out on the leafstalk to the leaf, where it would be in a very dangerous position, with slight foothold, and where it was very probable that, owing to the weight of its body, it would break off the leaf at the node and fall to the ground; or, the caterpillar must contrive to bring the leaf to itself in some way, while still keeping a sure foothold on the branch. To do this last required a little skill and I found that the caterpillar was equal to the task. Grasping the twig firmly with the anal and sometimes one or two pairs of the abdominal legs, it would extend the remaining portion of its body along the leafstalk, which it commenced eating. As soon as the leafstalk was about half eaten through, the caterpillar would recede a little and eat another place half through or more, and sometimes a third place. By this time the leafstalk had become so weakened that the leaf began to droop, and the caterpillar, reaching forward again as far as possible and grasping the stalk beyond the first incision, was able to bend it, and, drawing the leaf up to itself, eat it without loosing its sure foothold on the tree.

Sometimes the leafstalk was eaten through a little too far, or broke off in bending, which accounted for the green leaves found on the ground. 

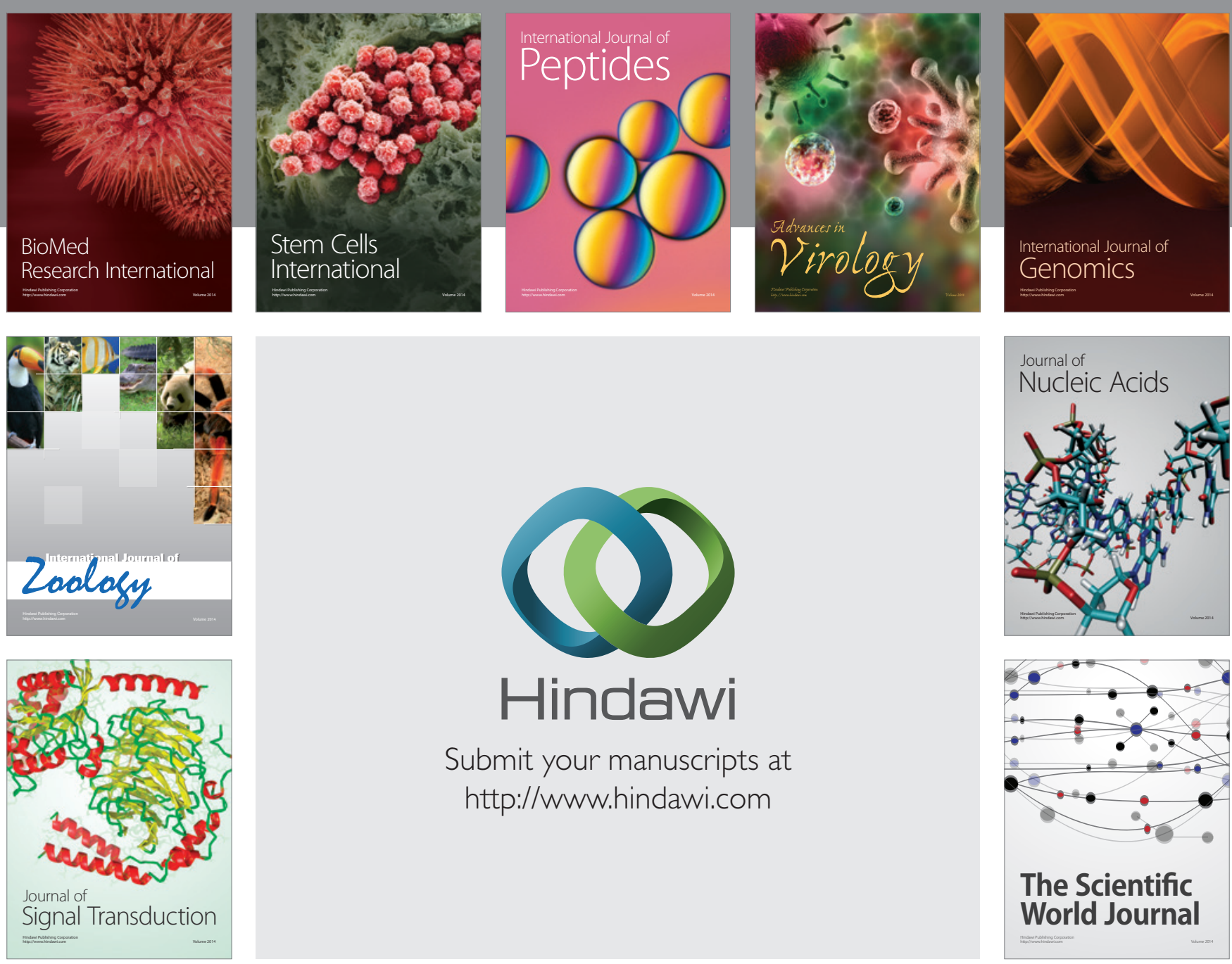

Submit your manuscripts at

http://www.hindawi.com
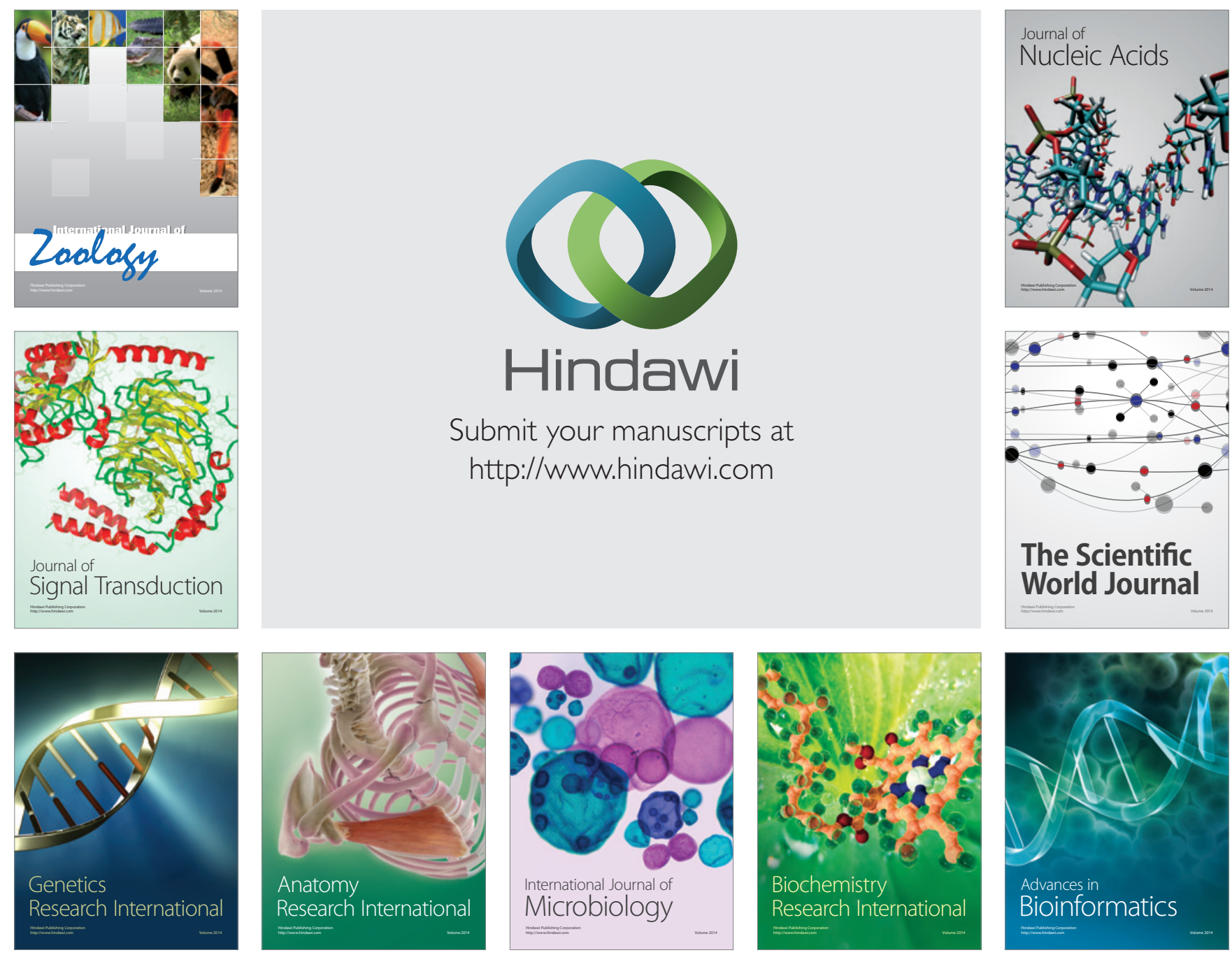

The Scientific World Journal
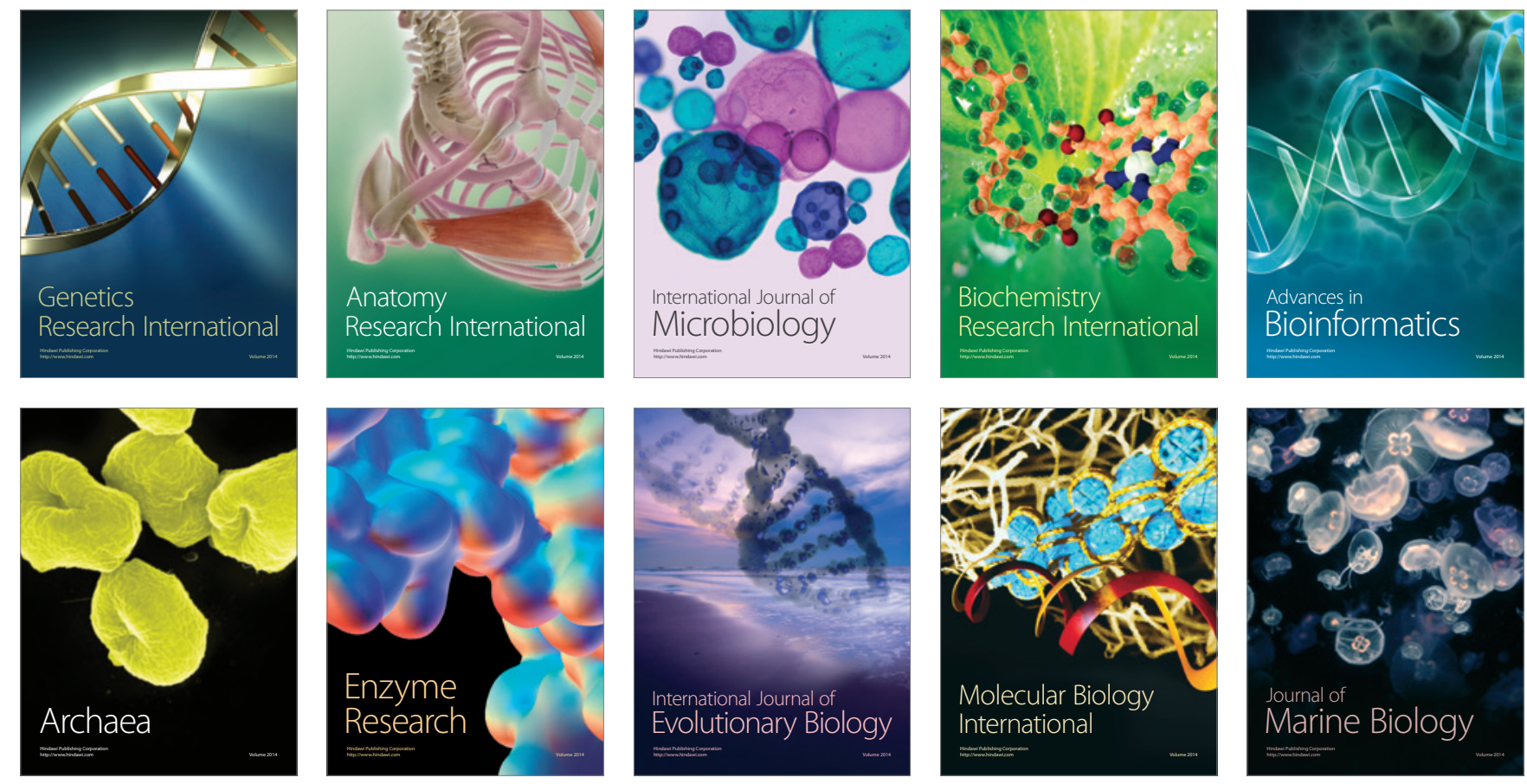